\title{
Current Training of Chinese Football and Its Development Countermeasures
}

\author{
Yang Tang \\ Hubei Business College \\ Wuhan, China
}

\begin{abstract}
Football is a popular mass sports activity in China. The level of football training has a direct impact on the development and popularization of football in China. This paper discusses the development strategy of football training in China by analyzing the current situation of football training.
\end{abstract}

\section{Keywords-football; training; development countermeasures}

\section{INTRODUCTION}

Football is one of the most widely played sports in the world and is deeply loved by people all over the world. Football training plays an important role in promoting the popularization of football and improving the football competition. At present, the development and popularity of football training are directly related to the future development of Chinese football. Only when the football training carried out by all classics is well developed, can the development of Chinese football be greatly improved, and the level of Chinese football makes great progress, realizing a real prosperity. However, at present, China's football training system is not sound. The training is unsatisfactory, the masses do not have high enthusiasm in football training is not high and football has not been widely promoted in the country. In view of this, it is necessary to deeply analyze the current situation of football training in China, so as to formulate development countermeasures suitable for China's national conditions and effectively reverse the current situation. With the goal of popularization and development of football, we can lay a solid foundation for the take-off of Chinese football.

\section{CURRENT Football Training Status}

At present, China's football training mainly includes campus football training, off-campus interest training, club professional echelon training and other forms of training. One is the campus football training. It mainly relies on the training of students' interests and skills on campus. It is mainly aimed at stimulating students' interests and exercising their physical functions. Most of the teachers are non-football professional physical education teachers concurrently. Students practice whatever the teacher arranges. The training is not systematic and teachers are not professional. The problem caused by this mode is that the students after training have more solitary movements. The training is not systematic, which is difficult to form professional competition. The training students cannot serve as a reserve talent of China's football major. Second, the off-campus interest training, mainly for the training of interests and hobbies. It is mainly serving parents to exercise their children or to meet their children's interests and needs. The level of training institutions is uneven and cannot provide China's football professional reserve talents. Third, the club professional echelon training. Comparatively speaking, the echelon training of the club has the characteristics of strong professionalism, quick results and systematic training content. After professional echelon training, trainees can improve their competitive ability and football training level in a short period of time. Trainees are reserve talents of football major in China. However, China's current football echelon construction is relatively lagging behind. Most football teams cannot establish a complete echelon system from children to adults, but only the T-15 echelon or above can be established. The echelons at lower levels cannot meet the development needs of Chinese football for they only depend on the cultivation of campus football or children's football school.

Compared with other sports, football has the characteristics of complexity and diversity in technology. As comrade Deng Xiaoping said, "football should be trained from a baby", which shows that football teaching is a long-term systematic project. However, China's current football training system is not perfect, which has certain restrictions on the development of China's football. First, the training level is uneven, the campus football training and professional football training cannot seamlessly dock with each other. It is mainly manifested in the lack of professional teachers in campus football training and the weak training ability of part-time physical education teachers, which leads to the unsystematic training of trainees and the inability of campus football training to provide talent support for the development of football. Second, compared with other sports, it is more difficult to carry out campus football because of the high requirements of the football field. At present, most schools in China have not established standardized football fields, which make it difficult to carry out campus football. Third, parents have low enthusiasm to ask their children to participate in the campus football training. Currently, education mode in China is still focused on exam-oriented education. For parents, football training is mainly used as a means to improve students' physical quality, but not to cultivate students to be a professional future football player, resulting in low popularity of football training on campus. Fourth, football rules are difficult to learn and master. In view of the particularity of offside, free kick and other football rules, it is difficult for students to master the rules. For students who are just beginning to learn football, it is even more difficult to master 
the difficult rules in football game practice, which makes it more difficult for students to learn and master the rules of football.

The above analysis proves that out of the current campus football training and students' own factors and other constraints, the development of campus football training has considerable limitations and difficulties. Therefore, to enhance the current campus football training and to promote the seamless connection between campus football training and professional echelon football training will become an important way to solve these problems.

\section{FoOtBALl TRAINING DEVELOPMENT STRATEGY}

\section{A. To Effectively Change the Guiding Ideology of Football Training}

The purpose of football training is to stimulate trainees' interest in football through professional training to promote football, to promote the popularity of football, to explore football talents, and to provide talent support for the development of Chinese football. Therefore, it is necessary to establish a more scientific and standardized football training system. However, in people's concept, football is to shoot balls. As a result, they often simply consider football as a very bitter and tired simple sports. In fact, football as a discipline, through systematic training, not only does it teach the trainees football skills and techniques, but also pays attention to let them master the characteristics of football sports. Therefore, it is necessary to combine the needs of trainees, effectively change the guiding ideology of football training, improve trainees' sports skills and football competitive ability to improve trainees' confidence in participating in football, and promote the popularization of Chinese football.

\section{B. To Actively Promote the Popularity of Football Training}

Taking the teaching principle of football training as the premise, we should continuously enhance the training effect of football training, enhance the interest of students in football and promote the popularization of football. It is its fierce antagonism and artistry makes football become the world's recognized first sport, which is also the reason why football has a very strong attraction to people. In the process of football training on campus, teachers should take it as their duty to stimulate and guide trainees' interest in learning and promote the improvement of training effect. By showing trainees football skills, teachers should stimulate trainees' interest and continuously promote the improvement of training effect. For example, making goals and passing skills are the most attractive points for trainees to learn. In the teaching practice of football class, teachers can consciously reduce the difficulty of goal scoring or decompose the difficulty movements, so as to actively encourage trainees to participate in more games and goals and let trainees feel the strong desire and sense of achievement. As a result, they can stimulate trainees' interest in participating in football and promote the popularity of football. In fact, this is the motivation for every soccer fan to get involved in the game in the first place. Similarly, good demonstration ability of physical education teachers is also indispensable. The outstanding football demonstration ability of teachers is also an important source of motivation for college students to actively study.

\section{Comprehensive Use of Various Training Methods}

In the discussion of football training method, the physical education teachers should combine their own teaching practice, give full play to their leading role in teaching, integrate football training with sports physiology, sports psychology and education, and found the football training methods in the midst of the common starting points.

One is the systematic training method. This method focuses on classifying the single technical actions in traditional training. In other words, basic football movements should be taken as the main clue in football training to decompose technical movements and strengthen systematic training. This training method takes intensive training as the main body, and reasonably joins some group antagonistic exercises, so as to improve the training interest of students. Therefore, its actions to be learned are closer to the actual combat of football. However, it is almost impossible to complete all the technical content for the systematic training method to use a wide variety of professional football skills in a relatively limited time. Therefore, only by finding the interconnection among various technologies, grasping the key components and reasonably combining them, can it achieve better training results.

Second, the step-by-step teaching method. This teaching method belongs to the modern teaching method, mainly designs and compiles the training content according to the trainee's age individual characteristic, carries out the classroom teaching training from the easy to the difficult, from the simple to the complex. From the perspective of physical education teaching, the step-by-step teaching method is mainly a training method based on the trainees' reception ability, according to the training plan, and completed by the trainees with the help of coaches. It is characterized by a high degree of independence and consciousness, which can simplify the football training process. In addition, it is conducive to strengthening the digestion and mastery of complex and difficult movements in football teaching, so as to shorten the training time. What's more, it can improve trainees' confidence and interest in learning, so as to better learn and master various technical movements.

Third, enlightening teaching method. The inspiration referred to in the training method mainly refers to a continuous exchange of information between the training environment and individuals, so as to inspire the training state of trainees, improve the level of competition. This teaching method requires the creation of a good training environment to stimulate the awareness of trainees, so as to fully stimulate the training potential of a psychological tendency. In this method, the education object of trainees is actually placed in the position of training subject. It takes the full expansion of trainees' abilities as the starting point of training, takes the personality, characteristics, development needs, physiological functions and psychological activities of trainees as the main body, which plays a significant role in cultivating the individualized psychology of trainees. 
Fourth is the transfer of teaching method. Football skills mastered in training can affect the learning and mastering of new skills, which is also known as the interaction of skills. Once mastered skills have a positive impact on the formation of new skills, it can well promote the generation of new skills, which is called skill transfer. This method plays a very important role in the training of football programs. It can divide football skills and tactics according to different categories, and then form regularity from the easy to the difficult, from the simple to the complex. Half the effort, twice the result. Fifth, the micro-teaching method. This teaching method is a kind of training activity completed in the form of group confrontation in a short period of time according to scientific training means. This teaching method can be summarized in a few words, that is, miniaturization of training content, standardization of skill movements, audio-visual recording of the process, and timely discussion and evaluation. The so-called micro, mainly refers to micro, fragments and small steps; micro-teaching aims to divide some complex contents into a large number of easy and single teaching ability. This teaching method has a significant effect at the beginning of football teaching.

\section{Improving the Quality of Coaches}

Coaches play an active role in the training of football. Football coaches have professional theoretical level, professional training ability and experience, and the ability to apply multiple disciplines to carry out scientific training and other aspects, which play a very important role in sports training results. At present, most of China's football coaches are talents who have received professional football training. These coaches are quite familiar with the theoretical knowledge of professional training but lack the experience of organizing personnel training. Therefore, in order to effectively improve the football skills of trainees, it is difficult to carry out high-level training. Therefore, it is necessary to carry out professional training to improve the professional level and professional ability of football coaches. In this way, they can use more advanced football training concept and football technology to guide players and conduct standardized training and scientific control of the training process of the trained players, so as to more effectively improve the football training level of the trained groups and the performance of the game. Therefore, we should formulate practical training plans for coaches and assign them to participate in various business learning and training. Since football coaches in China are all part-time coaches, and their own jobs are physical education teachers in various schools, they have extremely heavy teaching and scientific research tasks at ordinary times. As a result, it is difficult for football coaches to devote their energy to the training of football sports, let alone medical supervision and training research. At the same time, the implementation of the competition mechanism for football coaches is the most ideal way to select professional training personnel. In view of this, it is necessary to establish and improve a complete set of regulations on competitive recruitment of football coaches. We should carry out the competitive system of football coaches with the survival of the fittest as the main characteristic and select the coaches with excellent quality to be the football training and teaching work. In this way, the professional dedication and sense of responsibility of coaches can be better stimulated, which is conducive to the improvement of football training quality and the scientific and standardized football training.

\section{E. Adopting a Comprehensive and Reasonable Evaluation Method}

When evaluating the learning of trainees, we should pay attention to the comprehensiveness of the evaluation content. The evaluation methods can be divided into quantitative and qualitative methods, and the evaluation methods should be diversified. The implementation of teaching evaluation should not only assess the trainees' mastery of football technology and skills, but also consider process evaluation, which is carried out according to the individual progress of trainees and the degree of goal realization.

\section{CONCLUSION}

To sum up, campus football plays a very important role in Chinese football. The better the development of campus football is, the deeper and stronger the foundation of Chinese football will be. In this way, Chinese football will finally prosper in the future. Therefore, in view of the current situation of campus football teaching, we should actively adopt corresponding strategies and vigorously implement campus football, so as to make our own contribution to the development of Chinese football.

\section{REFERENCES}

[1] Cai Lixin, On sports quality and reform of college PE teaching [M]. Beijing: Yuanfang Press, 2002 (in Chinese)

[2] Lu Haiyan, Theoretical and practical studies on cultivation of sports ability of college students in new era [J]. Science and Technology Innovation Herald, 2008 (1) (in Chinese)

[3] Niu Bo, How to improve teaching quality of football skills course [J]. Sports World (Scholarly), 2009 (1) (in Chinese)

[4] Zhan Chongjiang, Status and Development Strategy Study on Football Optional Subjects - Take Zhejiang Forestry College for example [J]. Journal of Hubei Sports Science, 2010 (2). (in Chinese) 